\title{
Sacred geometry
}

\section{Abstract}

Sacred Geometry is a description of the use of fingerprint classifications in a geometric location. The purpose of the application is to analyze the position of a given code on a chart which is a display of an entire sequence of fingerprint codes. Through this method, with the understanding that mathematics is an exact science, the interpretation thereof allows us to examine the compatibility of groups of individuals who maintain a given geometric display, the ability to work together in harmony. This concept asserts its foundation on the dimensions of the perimeter of the Great Pyramid Khufu in Giza Egypt, which reflects time and space in its construction.
Volume 2 Issue 2 - 2016

\section{Andres JWashington}

Fingerprint Geometric Analysis, USA

Correspondence: Andres JWashington, Fingerprint Geometric Analysis, Post Office Box 165 Bronx, New York 1045I-0I65, USA, Tel 91 49603526,Email director@ dermatoglyphics.com

Received: November 19, 2015 | Published: February II, 2016
The concept of sacred geometry consists of two components

i. The fingerprint diagonal reverses sequence arrangement.

ii. The primary classification analysis.

The original sequence

\begin{tabular}{|c|c|c|c|c|c|c|c|}
\hline 111 & IIO & 101 & 100 & OII & OIO & OOI & 000 \\
\hline 111 & II I & III & 111 & III & 111 & III & 111 \\
\hline III & IIO & 101 & 100 & OII & OIO & $\mathrm{OOI}$ & 000 \\
\hline IIO & IIO & 110 & 110 & IIO & 110 & 110 & 110 \\
\hline 111 & IIO & 101 & 100 & OII & OIO & $\mathrm{OOI}$ & 000 \\
\hline IOI & IOI & IOI & 101 & IOI & I Ol & 101 & 101 \\
\hline 111 & 110 & 101 & 100 & OII & OIO & OOI & 000 \\
\hline 100 & 100 & 100 & 100 & 100 & 100 & 100 & 100 \\
\hline 111 & IIO & IOI & 100 & OII & OIO & OOI & 000 \\
\hline O II & OII & OII & OlI & OII & OII & O II & 011 \\
\hline 111 & 110 & 101 & 100 & OII & OIO & OOI & 000 \\
\hline OIO & OlO & OIO & OIO & OlO & OIO & OlO & 010 \\
\hline 111 & 110 & 101 & 100 & OlI & OIO & OOI & 000 \\
\hline OOI & OOI & OOI & $\mathrm{OOI}$ & $\mathrm{OOI}$ & $\mathrm{OOI}$ & $\mathrm{OOI}$ & OOI \\
\hline 111 & 110 & 101 & 100 & 011 & 010 & 001 & 000 \\
\hline 000 & 000 & 000 & 000 & 000 & 000 & 000 & 000 \\
\hline
\end{tabular}

\section{The fingerprint diagonal reverses sequence arrangement}

The original sequence is for the sixty-four possibilities when the \# 2,3,4,7,8 and 9 fingers are considered; this sequence only includes the inner and outer loops. The Original Sequence is arranged in the following order:

\begin{tabular}{|l|l|l|l|l|l|l|l|}
\hline 1 & 2 & 3 & 4 & 5 & 6 & 7 & 8 \\
\hline 9 & 10 & 11 & 12 & 13 & 14 & 15 & 16 \\
\hline 17 & 18 & 19 & 20 & 21 & 22 & 23 & 24 \\
\hline 25 & 26 & 27 & 28 & 29 & 30 & 31 & 32 \\
\hline 33 & 34 & 35 & 36 & 37 & 38 & 39 & 40 \\
\hline 41 & 42 & 43 & 44 & 45 & 46 & 47 & 48 \\
\hline 49 & 50 & 51 & 52 & 53 & 54 & 55 & 56 \\
\hline 57 & 58 & 59 & 60 & 61 & 62 & 63 & 64 \\
\hline
\end{tabular}

Due to the fact that the inked fingerprint is in actual reverse, (Mirroring) it has been determined that the original sequence would be arranged in reverse diagonally (The First Reference Sequence) displaying a different perspective of the total possibilities in relation to each other.

The first reference sequence

\begin{tabular}{|l|l|l|l|l|l|l|l|}
\hline 1 & 9 & 15 & 21 & 25 & 29 & 31 & 64 \\
\hline 56 & 2 & 10 & 16 & 22 & 26 & 63 & 32 \\
\hline 50 & 55 & 3 & 11 & 17 & 62 & 27 & 30 \\
\hline 44 & 49 & 54 & 4 & 61 & 18 & 23 & 28 \\
\hline 40 & 43 & 48 & 60 & 5 & 12 & 19 & 24 \\
\hline 36 & 39 & 59 & 47 & 53 & 6 & 13 & 20 \\
\hline 34 & 58 & 38 & 42 & 46 & 52 & 7 & 14 \\
\hline 57 & 33 & 35 & 37 & 41 & 45 & 51 & 8 \\
\hline
\end{tabular}

The first reference sequence

\begin{tabular}{|l|l|l|l|l|l|l|l|}
\hline 111 & 111 & 001 & 011 & 111 & 011 & 001 & 000 \\
111 & 110 & 110 & 101 & 100 & 100 & 100 & 000 \\
\hline 000 & 110 & 110 & 000 & 010 & 110 & 001 & 000 \\
001 & 111 & 110 & 110 & 101 & 100 & 000 & 100 \\
\hline 110 & 001 & 101 & 101 & 111 & 010 & 101 & 010 \\
001 & 001 & 111 & 110 & 101 & 000 & 100 & 100 \\
\hline 100 & 111 & 010 & 100 & 011 & 110 & 001 & 100 \\
010 & 001 & 001 & 111 & 000 & 101 & 101 & 100 \\
\hline 000 & 101 & 000 & 100 & 011 & 100 & 101 & 000 \\
011 & 010 & 010 & 000 & 111 & 110 & 101 & 101 \\
\hline 100 & 001 & 101 & 001 & 011 & 010 & 011 & 100 \\
011 & 011 & 000 & 010 & 001 & 111 & 110 & 101 \\
\hline 110 & 110 & 010 & 110 & 010 & 100 & 001 & 010 \\
011 & 000 & 011 & 010 & 010 & 001 & 111 & 110 \\
\hline 111 & 111 & 101 & 011 & 111 & 011 & 101 & 000 \\
000 & 011 & 011 & 011 & 010 & 010 & 001 & 111 \\
\hline
\end{tabular}

This diagonal reverse is then used to provide the arrangement of the Second Reference Sequence. 
The Second Reference Sequences

\begin{tabular}{|l|l|l|l|l|l|l|l|}
\hline 1 & 10 & 19 & 28 & 37 & 46 & 55 & 64 \\
\hline 2 & 11 & 20 & 38 & 47 & 56 & 3 & 12 \\
\hline 21 & 30 & 39 & 48 & 4 & 13 & 31 & 40 \\
\hline 5 & 14 & 23 & 32 & 6 & 24 & 7 & 16 \\
\hline 58 & 49 & 59 & 41 & 60 & 51 & 42 & 33 \\
\hline 61 & 52 & 34 & 25 & 62 & 53 & 44 & 35 \\
\hline 26 & 17 & 63 & 54 & 45 & 27 & 18 & 9 \\
\hline 57 & 50 & 43 & 36 & 29 & 22 & 15 & 8 \\
\hline
\end{tabular}

The second reference sequence works as verification in its outcome of how the first reference sequence was established. If the first reference sequence was not in proper arrangement, then the second reference sequence would not be in a uniform sequencing pattern. A close examination of the fingerprint codes found in the second reference sequence reveals a definite pattern along a diagonal basis.

\begin{tabular}{|c|c|c|c|c|c|c|c|c|}
\hline \multirow[b]{2}{*}{ Area "A" } & III & 110 & 101 & 100 & 011 & 010 & 001 & 000 \\
\hline & III & 110 & 101 & 100 & 011 & 010 & 001 & 000 \\
\hline \multirow{12}{*}{ Area "B" } & 110 & 101 & 100 & 010 & $\overline{001}$ & 000 & 101 & 100 \\
\hline & III & 110 & 101 & 011 & 010 & 001 & III & 110 \\
\hline & 011 & 010 & 001 & 000 & 100 & 011 & 001 & 000 \\
\hline & 101 & 100 & 011 & 010 & 111 & 110 & 100 & 011 \\
\hline & 011 & 010 & 001 & 000 & 010 & 000 & 001 & 000 \\
\hline & III & 110 & 101 & 100 & 111 & 101 & I II & 110 \\
\hline & 110 & 111 & 101 & III & 100 & 101 & 110 & III \\
\hline & 000 & 001 & 000 & 010 & 000 & 001 & OlO & OII \\
\hline & 011 & 100 & 110 & 111 & 010 & 011 & 100 & 101 \\
\hline & 000 & 001 & 011 & 100 & 000 & 001 & 010 & 011 \\
\hline & 110 & 111 & 001 & 010 & 011 & 101 & 110 & IIII \\
\hline & 100 & 101 & 000 & 001 & 010 & 100 & 101 & 110 \\
\hline \multirow{2}{*}{ Area "C" } & III & 110 & 101 & 100 & 011 & 010 & 001 & 000 \\
\hline & 000 & 001 & 010 & OII & 100 & 101 & 110 & 111 \\
\hline
\end{tabular}

It should be noted that the second reference sequence has been divided into three areas; described as area A, area $\mathrm{B}$, and area $\mathrm{C}$. In area "A" the diagonal of each box contains its opposite code. In area " $\mathrm{B}$ " and " $\mathrm{C}$ " the diagonal of each box contains the same code in reverse.

\begin{tabular}{|l|l|l|l|l|l|l|l|}
\hline 1 & 10 & 19 & 28 & 37 & 46 & 55 & 64 \\
\hline 2 & 11 & 20 & 38 & 47 & 56 & 3 & 12 \\
\hline 21 & 30 & 39 & 48 & 4 & 13 & 31 & 40 \\
\hline 5 & 14 & 23 & 32 & 6 & 24 & 7 & 16 \\
\hline 58 & 49 & 59 & 41 & 60 & 51 & 42 & 33 \\
\hline 61 & 52 & 34 & 25 & 62 & 53 & 44 & 35 \\
\hline 26 & 17 & 63 & 54 & 45 & 27 & 18 & 9 \\
\hline 57 & 50 & 43 & 36 & 29 & 22 & 15 & 8 \\
\hline
\end{tabular}

The second reference sequence

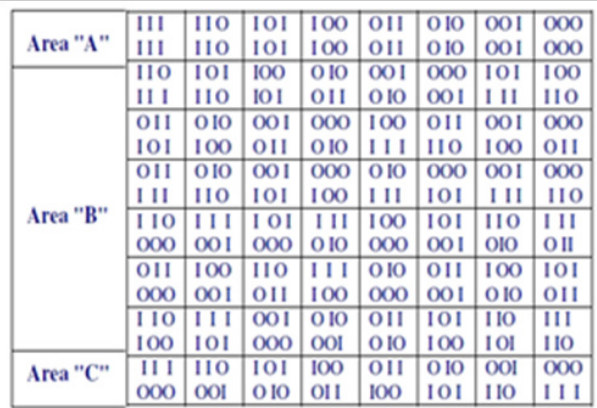

\section{Definitions}

\section{Includes}

In the display of an extended geometric area for a given code, any code which occupies the area by which two lines join together, forming an angle, or any code which is used to create the lines which provide the design for the given code in the original sequence, the first reference sequence or the second reference sequence is therefore included in the structure of that code's design. All codes which are included represent personalities that are compatible with one another. This is because all of the aforementioned codes are required to create the geometric design.

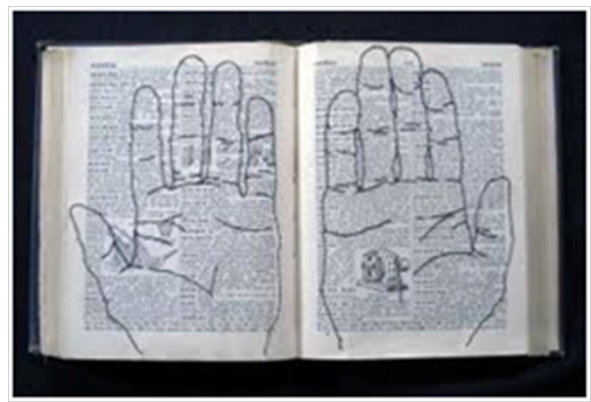

\section{Encompassed}

In the display of an extended geometric area for a given code, any code(s) which are surrounded by the geometric design and is not included in the makeup of that design and is not intersected by any of the lines which makeup that design is therefore encompassed within the extended geometric area. Geometric codes which are encompassed represent the personalities of persons that can be controlled by individuals who show in the display codes which are used to create the extended geometric area.

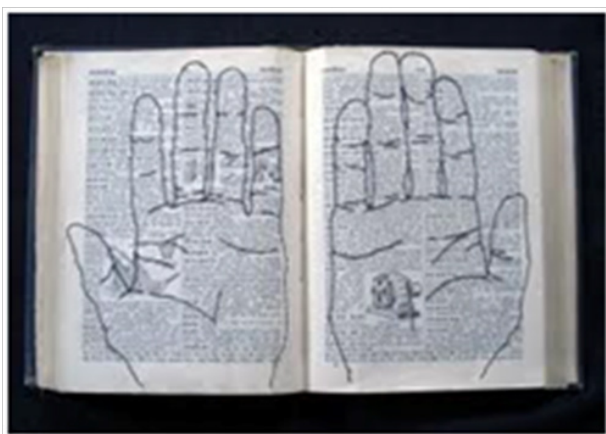




\section{Intersected}

In the display of an extended geometric area for a given code, any code which is crossed by the line(s) which make up the geometric design is in turn intersected by those lines. The codes which are intersected are the codes of persons who are incompatible with persons who are represented by the codes which are used to create the geometric design. This is because the intersection of a code is an offence to the geometric position of that code.

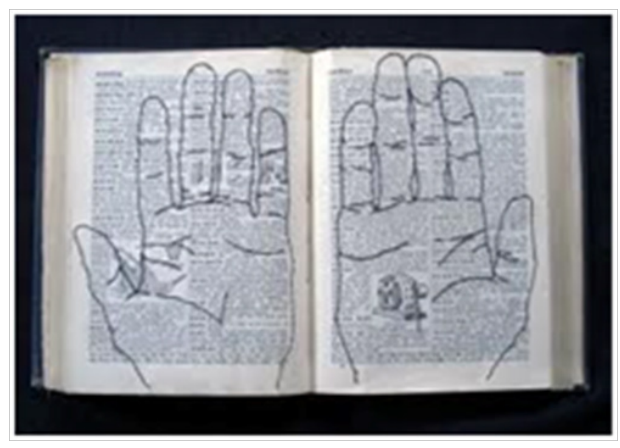

Example \Original Sequence

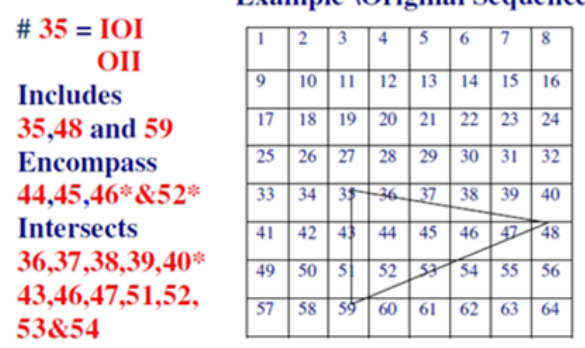

Example 1 Original Sequence

\begin{tabular}{|c|c|c|c|c|c|c|c|c|}
\hline $\begin{array}{r}\# 35=\text { IOI } \\
\text { OII }\end{array}$ & 1 & 2 & 3 & 4 & 5 & \begin{tabular}{|l|}
6 \\
\end{tabular} & \begin{tabular}{|l|}
7 \\
\end{tabular} & 8 \\
\hline Includes & 9 & 10 & 11 & 12 & 13 & \begin{tabular}{|l|}
14 \\
\end{tabular} & 15 & 16 \\
\hline 35,48 and 59 & 17 & 18 & 19 & 20 & 21 & 22 & 23 & 24 \\
\hline Encompass & 25 & \begin{tabular}{l|}
26 \\
\end{tabular} & 27 & 28 & 29 & 30 & \begin{tabular}{|l|}
31 \\
\end{tabular} & 32 \\
\hline $44,45,46^{\circ} \& 52^{\circ}$ & 33 & 34 & 35 & 36 & 37 & 38 & \begin{tabular}{|l|}
39 \\
\end{tabular} & 40 \\
\hline Intersects & 41 & 42 & 43 & 44 & 45 & 46 & 47) & $\frac{78}{48}$ \\
\hline $36,37,38,39,40^{\circ}$ & 49 & 50 & 5 & 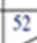 & 58 & 54 & 55 & 56 \\
\hline $\begin{array}{l}43,46,47,51,52, \\
53 \& 54\end{array}$ & 57 & 58 & 59 & 60 & 61 & 62 & 63 & 64 \\
\hline
\end{tabular}

\begin{tabular}{|c|c|c|c|c|c|c|c|}
\hline $\begin{array}{l}111 \\
\text { III }\end{array}$ & $\begin{array}{l}\text { IIO } \\
\text { III }\end{array}$ & $\begin{array}{l}\text { IOI } \\
\text { IIII }\end{array}$ & $\begin{array}{l}100 \\
111\end{array}$ & $\begin{array}{l}\text { OII } \\
\text { III }\end{array}$ & $\begin{array}{l}\text { O1O } \\
\text { III }\end{array}$ & $\begin{array}{l}\text { OOI } \\
\text { III }\end{array}$ & $\begin{array}{l}000 \\
111\end{array}$ \\
\hline III & IIO & IOI & 100 & OII & OIO & $\mathrm{OOI}$ & 000 \\
\hline 110 & 110 & 110 & 110 & 110 & 110 & 110 & 110 \\
\hline III & IIO & IOI & 100 & OII & OIO & $\mathrm{OOI}$ & 000 \\
\hline IOI & IOI & IOI & 101 & IOI & $10 \mathrm{OI}$ & $10 \mathrm{OI}$ & 101 \\
\hline 111 & 110 & 101 & 100 & OII & $\mathrm{OlO}$ & OOI & 000 \\
\hline 100 & 100 & 100 & 100 & 100 & 100 & 100 & 100 \\
\hline 111 & IIO & 101 & 100 & OlI & OIO & $\mathrm{OOI}$ & 000 \\
\hline O II & OII & ofl & Oा1 & Olt & - 11 & O II & OII \\
\hline 111 & 110 & $1 \phi 1$ & 100 & OII & OIO & $\overline{001}$ & 000 \\
\hline OIO & OIO & olo & $\mathrm{OlO}$ & $\mathrm{OIO}$ & 010 & бо & 010 \\
\hline 111 & 110 & $1 \phi 1$ & 100 & 04 & OlO & OOI & 000 \\
\hline $\mathrm{OOI}$ & $\mathrm{OOI}$ & OOI & eer & $\mathrm{OOI}$ & $\mathrm{OOI}$ & $\mathrm{OOI}$ & 001 \\
\hline 111 & 110 & 101 & 100 & 011 & 010 & 001 & 000 \\
\hline 000 & 000 & 000 & 000 & 000 & 000 & 000 & 000 \\
\hline
\end{tabular}

Primary classification first reference sequence

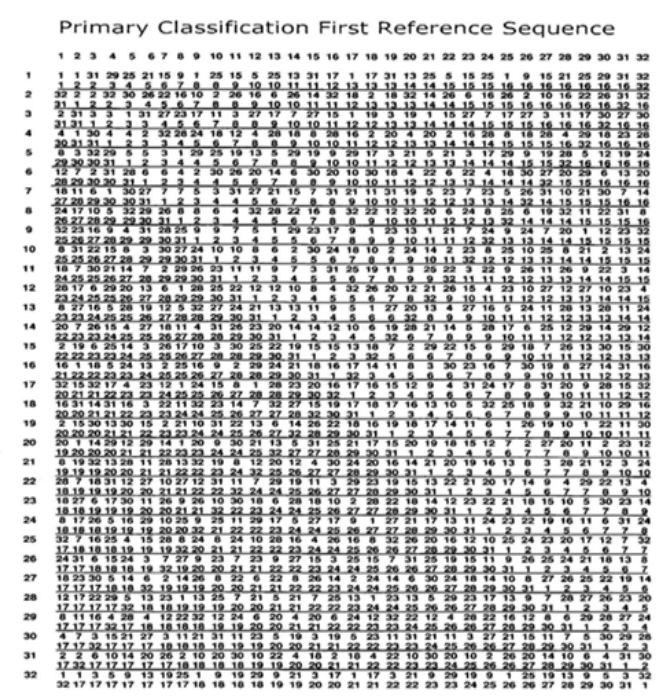

a. Primary classification 12 over 12

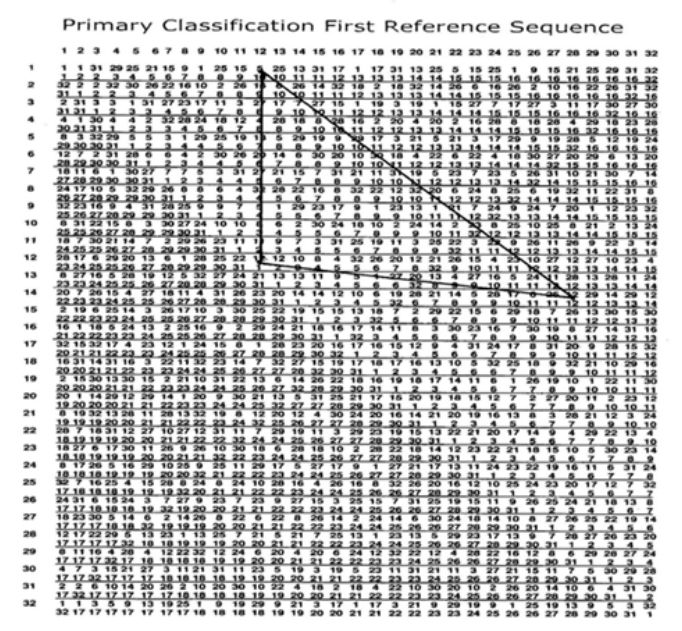

b. Primary classification 18 over 30

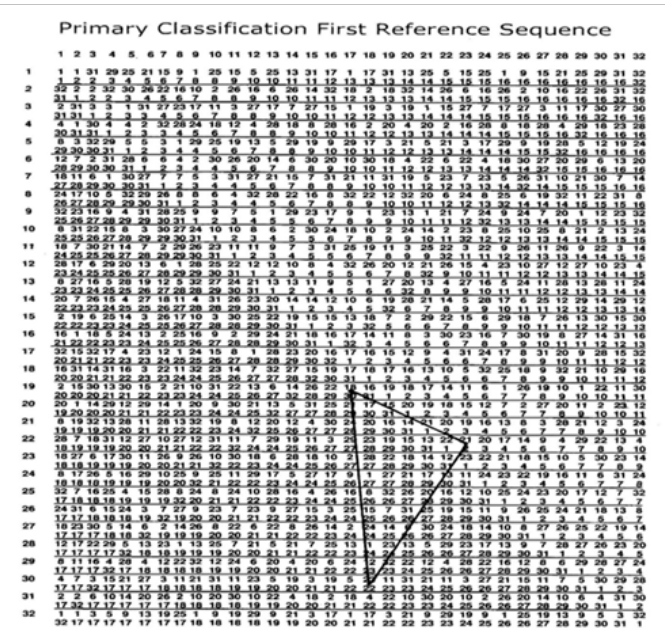




\section{c. Primary classification 11 over 27}

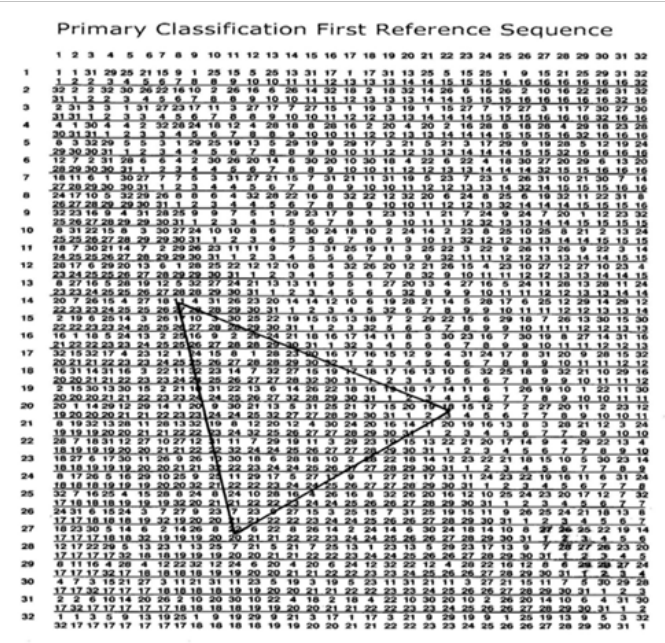

d. Primary classification 3 over 25

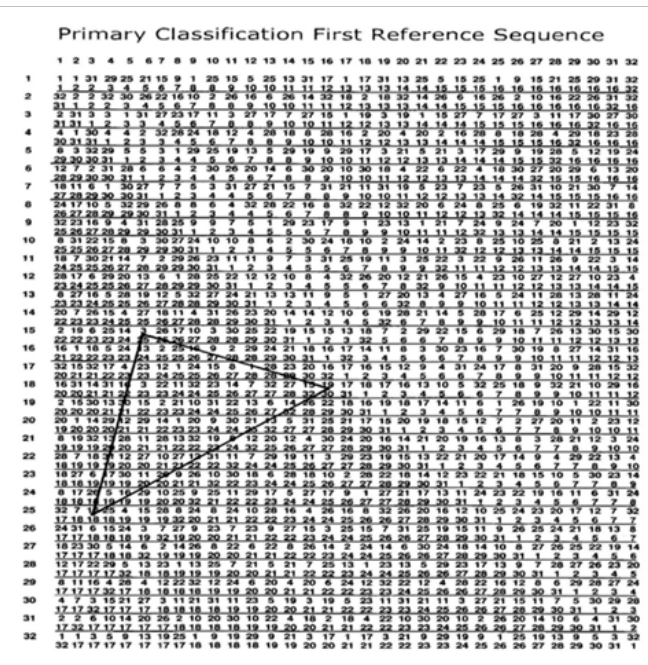

\section{e. Primary classification 19 over 17}

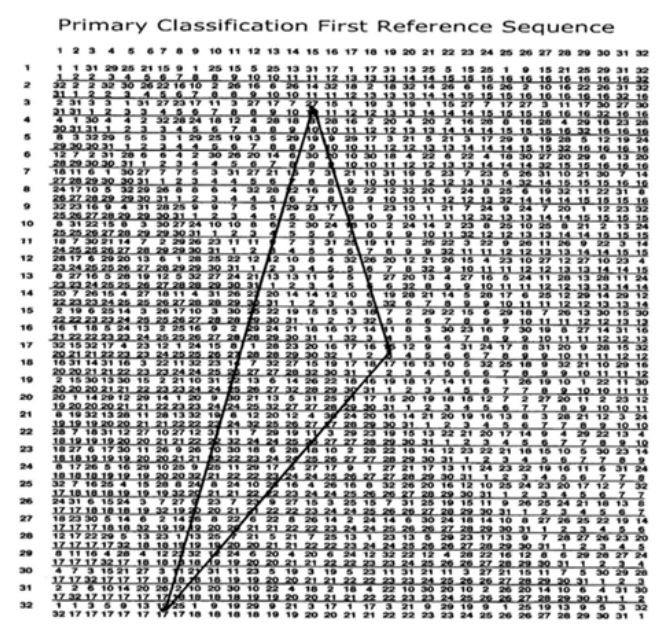

\section{Primary classification analysis}

To file fingerprint records by the primary classification, a reasonable distribution of codes over the 1024 classifications had to be considered. Fingerprint technicians took into account the phenomenon of different populations across a geographical location and it was best determined that the ten digits should be assigned numerical values (in most cases) in the following way: $1=16,2=16,3=8,4=8,5=4$, $6=4,7=2,8=2,9=1$ and $10=1$. Thus the total numerical values of the even digits plus 1 for consistency is reflected as the numerator of the primary classification code while the total numerical values of the odd digits plus 1 for consistency is reflected as the denominator of the primary classification code.

\begin{tabular}{|l|l|l|l|l|}
1 & \multicolumn{1}{c}{3} & \multicolumn{1}{c}{3} & 5 \\
\hline 16 & 16 & 8 & 8 & 4 \\
\hline 4 & 2 & 2 & 1 & 1 \\
\hline 6 & 7 & 8 & 9 & 10 \\
\hline
\end{tabular}

However, today most agencies or departments do not file fingerprints according to the Henry System of Fingerprint Classification and Filing, they using the Automated Fingerprint Identification System (AFIS) and (IAFIS) entry and comparison to store and retrieve fingerprint minutiae.

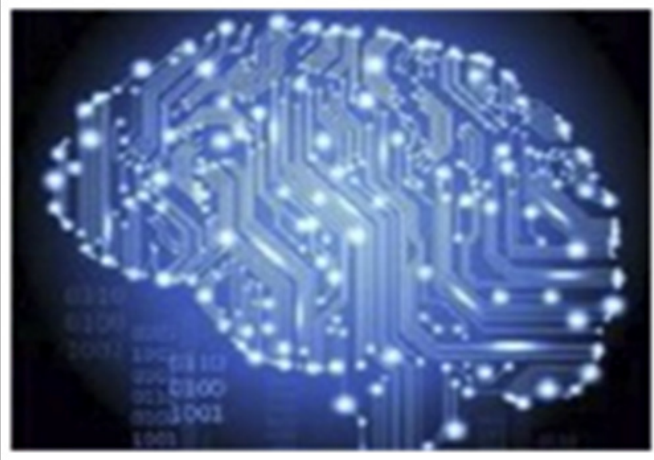

In Fingerprint Geometric Analysis the concept of the primary classification is presented from a different perspective. The 1024 classification codes of the primary are displayed in a multi-sequential primary classification chart which is an example of the Fingerprint Diagonal Reverse Sequence Arrangement. With this an individual code can reside within up to three different locations forming a geometric design which is triangular or linear. There is however additional adjustments. The numerical values are assigned to the digits in a different way. Here we take into account the frequency of whorl patterns over the ten set of fingerprints. Fingerprints on digits with a high frequency of whorls are assigned a lower numerical value while fingerprints with a low frequency of whorls are assigned a higher numerical value. This would make all pattern frequencies more equal to the other. As before the addition of 1 to the numerical value(s) for consistency is included and the values of the right hand are presented over the values of the left hand instead of the value of even digits over odd. 


\section{Male frequency of whorl patterns}

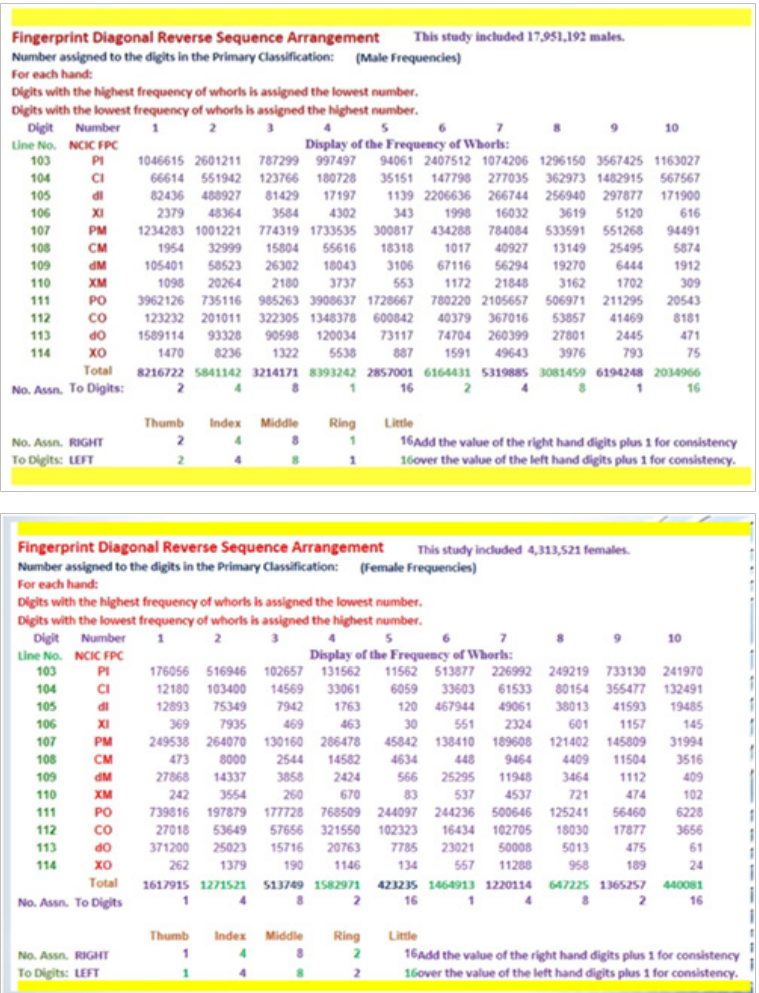

\section{Primary classification analysis}

Male \& Female Frequency of Whorl Patterns
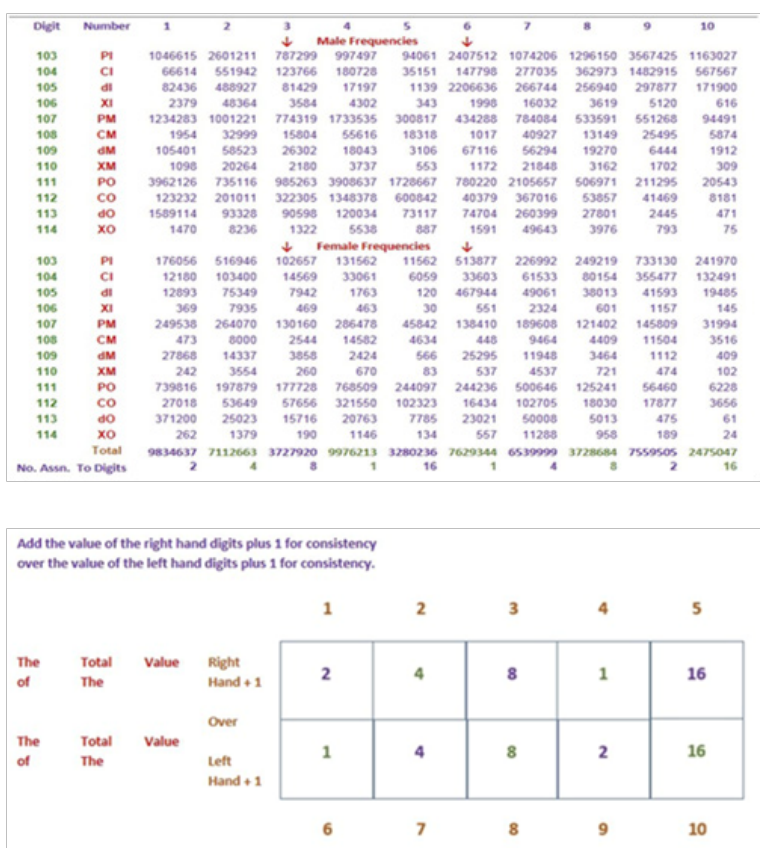

What is also essentially paramount to this analysis is the dimensions of the multi-sequential primary classification chart. The length of each side of the chart must be 9131 units of measurement to provide a perimeter of 36524 units of measurement. The presentation of this on a monitor must be reflected in the computer application. In this way accurate information for analysis will be provided.

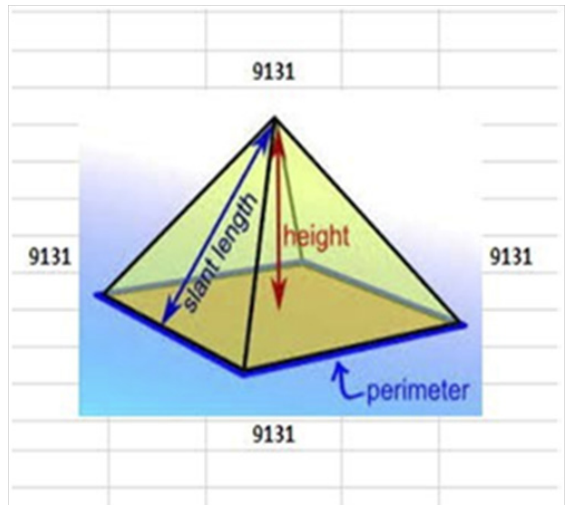

\section{The great pyramid Khufu at Giza, Egypt}

i. Each side of the base of the Great Pyramid is 9131 pyramid inches. (A pyramid inch is 2.5426924 centimeters.) This gives us a perimeter of 36524 pyramid inches $(9131 \times 4=36524)$.

ii. 36524 pyramid inches expresses three units of time; 365 for 365 days in a year, 52 for 52 weeks in a year and 24 for 24 hours in a day! In addition, $36524.22=$ the number of days in 100 years.

\section{The great pyramid}

9131 Pyramid inches $=365.2422$ Royal Egyptian Cubits .

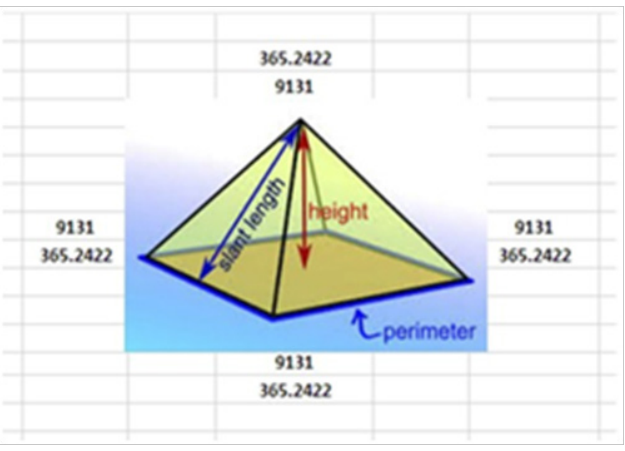

"This appears not to be a coincidence because the length of each side of the Great Pyramid's base is 365.2422 Royal Egyptian Cubits" ("pyramid cubits").

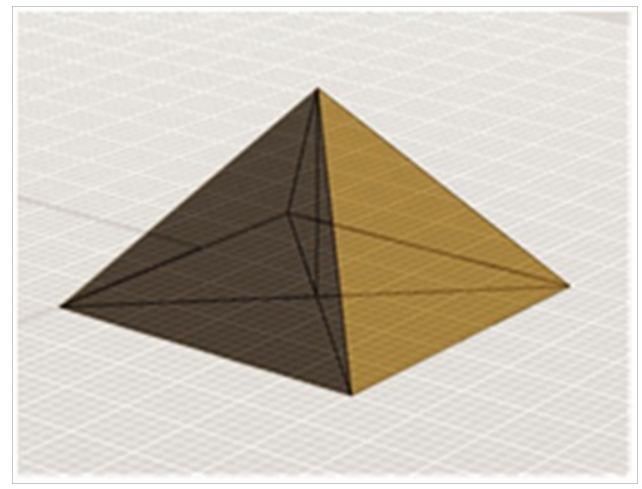




\section{NCIC FPC filing sequence formula}

This concept can be applied to the National Crime Information Center Finger Print Classification (NCIC FPC) Filing Sequence Formula.

\section{Let us see how this works}

NCIC FPC Filing Sequence Formula

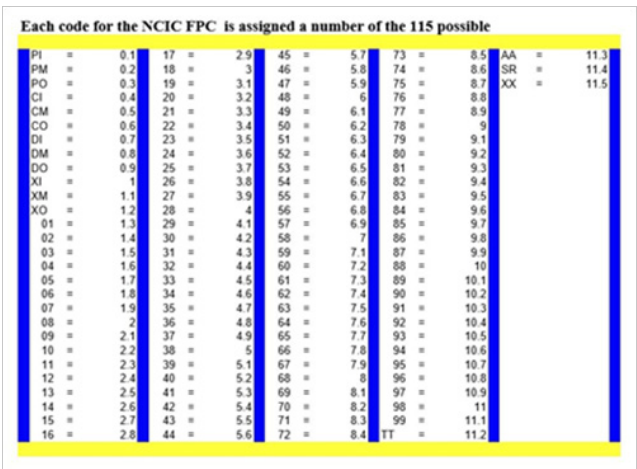

The NCIC FPC contains 20 characters, each pair of characters represents one digit beginning with the right thumb as the No. 1 digit and ending with the left little finger as the No. 10 digit; the left thumb is hen No. 6. For every consecutive pair of characters, one code can be assigned out of a possible 115 codes (from PI to XX). This means that there are actually only 10 individual segments for the NCIC FPC code, with each one maintaining a pair of the 20 characters to represent an individual code. Let $(\mathrm{X})$ equal the number of assigned to the NCIC FPC code. Each of the ten segments with the exception of segment $\# 1$, must be assigned a decimal number which shall be added to the assigned number for the given NCIC FPC Code.

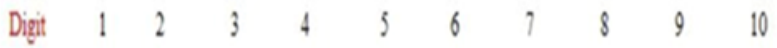 \\ Nimber \\ Asigned $\times$ X00001 $\times 00002 \times 00003 \times 00004 \times 00005 \times 00006 \times 00007 \times 00008 \times 00009$}

This adding of the decimal number to the assigned number for the NCIC FPC code must be done in order to establish a unique numerical value to each segment of the ten-segment unit. Segment number 1, however, need not be assigned a decimal value because the other nine segments maintain an identity distinguishable from it. (The reason for choosing \#1 segment as the one which shall not be assigned a decimal value is because \#1 segment is the only segment which can provide us with the lowest possible number in the calculation if no decimal was to be added to it.) It can be noted that in this way no two or more segments can provide the same exact number. Furthermore, no two NCIC FPC codes can provide the same filing number, even if the original code appeared in a reverse sequence.

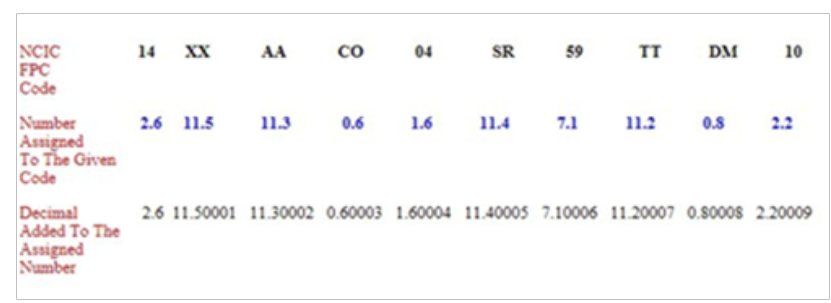

After the decimal number is added to the assigned number for the NCIC FPC code, multiplication takes place. That is, \#1 segment times \#2 segment and that product multiplied by \#3 segment, and so on until \#10 segment has been included in the multiplication. The end product shall provide the filing cation for the given NCIC FPC code. When there are ten segments and 115 possible codes for each segment, the total number of combinations is $404,555,773,570,791,015,625$.

\section{NCIC FPC filing sequence formula}

\section{Example:}

i. (2.6) X (11.50001) X (11.30002) X (0.60003) X(1.60004) X $(11.40005) \mathrm{X}(7.10006) \mathrm{X}(11.20007) \mathrm{X}(0.80008) \mathrm{X}(2.20009)$ $=517,628.2327$.

ii. In conclusion, the NCIC FPC code, 14XXAACO04SR59TTDM10.

iii. Would be filed as 517,628.2327 between.

iv. 0.000000000100451 and $40,457,160,428$.

This formula was designed to encourage the development of a computer application that would display the geometric location of an NCIC FPC code so that it can be applied to the Fingerprint Diagonal Reverse Sequence Arrangement.

\section{Acknowledgments}

None.

\section{Conflicts of interest}

The author declares that there are no conflicts of interest. 